\title{
Protein deprivation and food-related risk-taking preferences of rhesus monkeys
}

\author{
CHARLES W. HILL, ARTHUR J. RIOPELLE, and ALAN R. KING \\ Louisiana State University, Baton Rouge, Louisiana
}

\begin{abstract}
The relative preferences of four rhesus monkeys for reward probability versus reward amount when they were maintained on a low-protein $(3.35 \%)$ diet were compared with those demonstrated when they were fed an adequate $(13.4 \%)$ protein diet. Four stimulus objects, each signifying a different combination of reward frequency and amount (100\%-one piece, $50 \%-2$ pieces, $33 \%$-three pieces, or $25 \%$-four pieces), were presented in pairs, one pair per daily session, with trial schedules providing the same amount of reward within each set of 12 trials. Selections of the more frequently rewarded objects, but with lesser amounts per trial, were significantly higher during the low-protein phase than during either the preceding or the following normaldiet phases. Protein deprivation produces a changed motivational state making these animals less tolerant of infrequent or postponed reinforcement.
\end{abstract}

Hungry animals scurry and scrounge for food. They rapidly learn to associate food with objects that signify its presence or location. They can also identify and repeatedly select which of two stimuli is the more likely to be accompanied by reward. When rhesus monkeys are confronted by and respond to discriminably different stimuli that are rewarded with different probabilities, they always opt for the more frequently rewarded object, the one that yields the greater amount over the long run (Meyer, 1960; Treichler, 1967; Treichler, Conner, \& Ricciardi, 1970). Furthermore, when offered a choice between stimuli that signify different incentive amounts, they prefer the object associated with the greater amount per trial (Meyer, 1951; Meyer, LoPopolo, \& Singh, 1966). When these two reward conditions are placed in opposition, so that the same total amount of reward will be obtained from either object over the long run (increased probability offset by decreased amount and vice versa), the monkeys tend to select the more frequently rewarded object with the lesser amount (MFLA), or else they allocate their responses indiscriminately between the two objects. They do not adopt a sustained preference for the stimulus signifying the less frequent but more amount (LFMA) of reward per trial (Behar, 1961).

The question of whether these preferences are dependent on a physiologically induced motivational state (specifically, one related to diet ade-

This work was supported in part by Grant HD-07479 from the National Institute of Child Health and Human Development of the National Institutes of Health. Requests for reprints should be addressed to Charles W. Hill, Department of Psychology, University of New Orleans, New Orleans, Louisiana 70148. quacy) arises. Would preferences be affected if the animals were deprived of some critical component of their diet, with or without a change in body weight? If the monkey were placed in a perturbed physiological state, would its preference for amount or relative frequency of food reward change?

We have shown previously that protein restriction drastically changes the preference of rhesus monkeys among various kinds of foods, making items that normally would be rejected out of hand acceptable (Hill \& Riopelle, 1975). Similarly, Zimmermann and Strobel (1969) have reported that the visual curiosity, a form of adventurousness, of protein-deprived monkeys is substantially reduced, and Zimmermann (1969) has found that deprived monkeys thus suppress their usual curiosityevoked stimulus preferences and that this suppression results in improved discrimination performance.

The purpose of our present study was to determine the effects of protein deprivation upon the development of preference patterns for relative frequency and amount of food.

\section{METHOD}

\section{Subjects \\ Four test-wise rhesus monkeys, Macaca mulatta, served as subjects. They had acquired considerable experience with discrimination-learning tasks of several kinds, including learn- ing sets. There were two males and two females, between 4 and 5 years of age.}

\footnotetext{
Apparatus

Test problems were presented in a modified Wisconsin General Test Apparatus having a sliding stimulus tray and a vertical opaque screen that concealed the tray from the subject between trials. Four three-dimensional stimulus objects, different in both shape and color, were employed throughout. Each object was arbitrarily assigned one of the following combinations of reward frequency and amount: $100 \%$ with one unit $(100 \times 1)$,
} 
$50 \%$ with two units $(50 \times 2), 33 \%$ with three units $(33 \times 3)$, and $25 \%$ with four units $(25 \times 4)$.

\section{Procedure}

The experiment was conducted in three phases (A, B, and C). The animals were fed a low-protein diet during Phase B. Similar testing procedures were employed throughout, with variations occurring only in number of trials per daily session and in the pattern of preliminary training. In each phase, six discrimination tasks were presented consecutively, one per session, for 96 trials each (48 trials in Phase A), and then the series was repeated. Each task involved two of the four objects, and their appropriate reward characteristics were applied through several restricted random series that provided the same total amount of food within each block of 12 trials, regardless of which object was consistently selected. These object pairs produced the following reward ratios: $100 \times 1$ vs. $25 \times 4=4: 1 ; 100 \times 1$ vs. $33 \times 3=3: 1$; $100 \times 1$ vs. $50 \times 2=2: 1 ; 50 \times 2$ vs. $25 \times 4=2: 1 ; 50 \times 2$ vs. $33 \times 3$ $=3: 2 ; 33 \times 3$ vs. $25 \times 4=4: 3$.

A unit of reward was a piece of commercial dry breakfast cereal, containing about $7 \%$ of the calories as protein, $85 \%$ as carbohydrates, and $8 \%$ as fat. The noncorrection method was employed. Several semirandom series of numbers were used to regulate the trial-by-trial locations of the objects on the tray and to designate the various reward characteristics.

Before each daily session, preliminary exposure to the two objects for that task was provided to acquaint the monkey with the particular reward frequencies and amounts associated with each object. The details of this training differed slightly during the three phases. During Phase A, each object was presented by itself for 12 trials, during which the monkey could note the frequency and amount of reward. During Phases B and C, there were 16 trials with each object-the first 4 trials were all baited with the appropriate amount of food and the final 12 trials were baited in accordance with the appropriate probabilities as well as the amounts. The point of this preliminary training was to acquaint the animals with the consequences of selecting the different stimuli. The monkeys, therefore, did not have to learn these outcomes during testing; they had only to express their preferences.

At least 2 weeks before beginning Phase $B$, all subjects were placed on a low-protein (3.35\%) diet (Riopelle, Hill, Li, Wolf, \& Seibold, 1974) that was isocaloric with their previous diet. They remained on this diet until the end of Phase $B$, at which time the monkeys were returned to their normal diet, containing $13.4 \%$ protein. At least 2 weeks then elapsed before Phase $C$ was begun. During the approximately 6 weeks from the end of Phase A to the end of Phase B, the deprived animals continued to eat their daily rations normally, and no dramatic weight losses were observed. Furthermore, we saw no marked difference in their testing behavior in the apparatus.

\section{RESULTS}

Protein deprivation enhances selection of the more frequently rewarded object. The percentage of MFLA selections over all object pairs was significantly higher during the low-protein phase $(\mathbf{8 0 . 8 \%})$ than during either the preceding $(67.5 \%)$ or the following $(66.3 \%$ ) normal-protein phase (see Table 1 ). Every animal increased its MFLA selections during Phase $B$ (deprivation) and reduced them again during Phase $\mathrm{C}$ (repletion). Among the six object pairs, only the one with the lowest reward ratio $(33 \times 3$ : $25 \times 4)$ produced an MFLA selection $(68 \%)$ below $75 \%$.
Table 1

Percentage of More Frequent Less Amount Selections During Phases A, B, and C, Together With Differences and Their Significance

\begin{tabular}{lccccc}
\hline Subject & $\begin{array}{c}\text { Phase } \\
\text { A }\end{array}$ & $\begin{array}{c}\text { Phase } \\
\text { B }\end{array}$ & $\begin{array}{c}\text { B - A } \\
\text { Difference }\end{array}$ & $\begin{array}{c}\text { Phase } \\
\text { C }\end{array}$ & $\begin{array}{c}\text { B - C } \\
\text { Difference }\end{array}$ \\
\hline 1 & 75.0 & 88.8 & 13.0 & 72.0 & 16.0 \\
2 & 60.0 & 75.0 & 15.0 & 58.0 & 17.0 \\
3 & 65.5 & 80.0 & 14.5 & 61.0 & 19.0 \\
4 & 69.5 & 80.0 & 11.5 & 74.0 & 6.0 \\
Group Mean & 67.5 & 80.0 & $13.3 \dagger$ & 66.3 & $14.5^{*}$ \\
\hline
\end{tabular}

Note-There were 576 trials/subject in Phase A and 1,152 trials/ subject in Phases $B$ and $C$. For all individual subject differences, $p<.001 . \quad{ }^{*} p<.01 . \quad t p<.001$.

If the animals had no strong stimulus preference (mostly during Phases $\mathrm{A}$ and $\mathrm{C}$ ), they adopted a position habit. Position habits, defined as responses to the left or the right foodwell on $75 \%$ or more of the trials per half-session regardless of the object covering it, developed when MFLA selections were weak and near $50 \%$. Over all three phases, $36 \%$ of the no-preference-level choices were accompanied by position habits.

\section{DISCUSSION}

These data clearly establish that rhesus monkeys, when transferred from an adequate to a low-protein diet, increase their preference for the reward that appears more frequently in opposition to the less frequent one although the latter provides the greater amount. This low-protein-induced effect was evident in all four subjects. There would seem to be little doubt but that protein deprivation increases the need for more continuous and consistent food intake rather than for the larger, although less probable, rewards.

These data and those reported earlier by Zimmermann and his colleagues (Zimmermann, 1969; Zimmermann, Geist, Strobel, \& Cleveland, 1974; Zimmermann \& Strobel, 1969) and ourselves (Hill \& Riopelle, 1975) support the view that, in the discrimination situation, a major effect of protein deprivation is a motivational change such that animals develop an inability to tolerate infrequent rewards, even though such rewards may be larger. The immediacy of food and its presence here and now become strong factors in guiding food-related behavior.

Throughout this study, near-chance MFLA selections were accompanied by position habits. When fed a normal protein diet, our animals were cognizant of the several reward alternatives associated with each object pair and were quite willing to employ the position habit as one means to obtaining the same overall amount of food. At the same time, 
they also employed a strategy of shifting their selections between the two objects regardless of tray side, indicating that they were unable to decide which of the two solutions was preferable.

\section{REFERENCES}

Behar, I. Learned avoidance of non-reward. Psychological Reports, 1961, 9, 43-52.

Hill, C. W., \& Riopelle, A. J. Protein deprivation in primates: VI. Food preferences of adult rhesus monkeys maintained on low-protein diets. Perceptual and Motor Skills, 1975, 41, 199-204.

MEYER, D. R. The effects of differential rewards on discrimination reversal learning by monkeys. Journal of Experimental Psychology, 1951, 41, 268-274.

Meyen, D. R. The effects of differential probabilities of reinforcement on discrimination learning by monkeys. Journal of Comparative and Physiological Psychology, 1960, 53, 173-175.

MEYer, D. R., LoPopolo, M. H., \& Singh, D. Learning and transfer in the monkey as a function of differential levels of incentive. Journal of Experimental Psychology, 1966, 72, 284-286.

Riopelle, A. J., Hill, C. W., Li, S. C., Wolf, R. H., Seibold,
H. R., \& Smith, J. L. Protein deprivation in primates: I. Nonpregnant adult rhesus monkeys. American Journal of Clinical Nutrition, 1974, 27, 13-21.

Treichle R, F. R. Reinforcer preference effects on probability learning by monkeys. Journal of Comparative and Physiological Psychology, 1967, 64, 339-342.

Treichler, F. R., Conner, J. B., \& Ricciardi, A. M. Probability learning and reversal by experimentally naive rhesus and squirrel monkeys. Learning and Motivation, 1970, 1, 411-419.

ZimmermanN, R. R. Effects of age, experience, and malnourishment on object retention in learning set. Perceptual and Motor Skills, 1969, 28, 867-876.

ZimmermanN, R. R., Geist, C. R., Strobel, D. A., \& Cleveland, T. J. Attention deficiencies in malnourished monkeys. In J. Cravieto, L. Hambreus, \& B. Vahlquist (Eds.), Early manipulation and mental development, Symposia of the Swedish Nutrition Foundation, XII. Uppsala: Almquist and Wiksell, 1974.

Zimmermann, R. R., \& Stroend, D. A. Effects of protein malnutrition on visual curiosity, manipulation, and social behavior in the infant rhesus monkey. Proceedings of the 77th Annual Convention of the American Psychological Association, 1969, 4, 241-242.

(Manuscript received December 8, 1981; revision accepted for publication November $9,1982$. 